\title{
COVID-19 and thrombosis: Prophylaxis and management
}

\author{
Kadir CANOĞLU(ID) \\ Bengü ŞAYLAN $(I D)$ \\ Tayfun ÇALIŞKAN(ID)
}

Clinic of Chest Diseases, Sultan 2. Abdülhamid Han Training and Research Hospital, Istanbul, Turkey

Sultan 2. Abdülhamid Han Ĕgitim ve Araştırma Hastanesi,

Göğüs Hastalıkları Kliniği, İstanbul, Türkiye
Cite this article as: Canoğlu K, Şaylan B, Çalışkan T. COVID-19 and thrombosis: Prophylaxis and management. Tuberk Toraks 2021;69(2):269-278.

\section{Yazıssma Adresi (Address for Correspondence)}

\section{Dr. Kadir CANOĞLU}

Sultan 2. Abdülhamid Han Eğitim ve

Araştırma Hastanesi,

Göğüs Hastalıkları Kliniği,

ISTANBUL - TÜRKIYE

e-mail: kadircano@gmail.com
CCopyright 2021 by Tuberculosis and Thorax. Available on-line at www.tuberktoraks.org.com

\begin{abstract}
COVID-19 and thrombosis: Prophylaxis and management

COVID-19 emerged in Wuhan, China in late December 2019, and WHO declared it a pandemic on March 11, 2020. The disease has a wide spectrum ranging from asymptomatic or mild disease to ARDS and death. There have been over 83.9 million cases with 1.8 million deaths worldwide. COVIDassociated coagulopathy appears to be an entity responsible for deaths. Thromboprophylaxis is recommended in patients with COVID-19 to prevent arterial and venous thromboembolism. Low molecular weight heparin such as enoxaparin is often recommended. However, there is still no consensus regarding the treatment dose and duration. The purpose of this review was to observe the pathogenesis of thromboembolic events in COVID-19, current thromboprophylaxis regimens, treatment dosage and duration with guidelines of international scientific institutions.
\end{abstract}

Key words: Anticoagulants; COVID-19; heparin; low-molecular-weight; thrombosis

ÖZ

COVID-19 ve tromboz: Profilaksi ve yönetimi

COVID-19 ilk olarak Çin'in Wuhan kentinde ortaya çıkmış ve 11 Mart 2020 tarihinde WHO pandemi ilan etmiştir. Asemptomatik ya da hafif hastalıktan ARDS ve ölüme kadar gidebilen geniş bir yelpazeye sahiptir. Tüm dünyada 83,9 milyon vaka ile birlikte 1,8 milyondan fazla ölüm görülmüştür. COVID'e bağlı koagülapati ölümlerden sorumlu antite olarak görülmektedir. COVID-19 hastalarında arteriyel ve venöz tromboemboliyi önlemek için tromboprofilaksi önerilmektedir. Genellikle enoksaparin gibi düşük molükül ağırıklı heparin önerilmektedir. Ancak, hala tedavi süresi ve dozu ile ilgili ortak görüş bulunmamaktadır. Bu derlemenin amacı, COVID-19'da tromboembolik olayların patogenezi, uluslararası rehberlerin güncel profilaksi önerileri, dozaj ve sürelerini incelemektir.

Anahtar kelimeler: Antikogülan; COVID-19; düşük molekül ağırlıklı heparin; tromboz 


\section{INTRODUCTION}

Coronavirus Disease-2019 (COVID-19) first appeared in Wuhan, China's Hubei province, in December 2019. After its rapid spread to many countries, it was declared as a pandemic by the World Health Organization (WHO) on March 11, 2020 (1). Although many patients experience mild symptoms, some may present with serious symptoms and have a severe clinical course, leading to multiple organ dysfunction syndrome (MODS) and death (2). At the time this article was written, over 1.8 million deaths and 83.9 million cases were encountered worldwide (3).

Since Ebola and cytomegalovirus (CMV) cause the development of disseminated intravascular coagulation (DIC), Marongiu et al. have proposed the hypothesis that abnormal laboratory parameters such as D-dimer and fibrin degradation products in COVID19 may be related to local DIC, such as pulmonary vascular thrombosis (4). Alveolar capillary microthrombi were 9 times more frequent in autopsy series of COVID-19 and influenza-A patients who developed acute respiratory distress syndrome (ARDS) (5). Arterial and venous thromboembolism is common in COVID-19. In the study of autopsy examinations of 12 deaths related to COVID-19, deep venous thrombosis (DVT), which was not diagnosed before death, was found in seven, and the direct cause of death in four patients was pulmonary embolism (6). WHO recommends pharmacological prophylaxis with low molecular weight heparin (LMWH) in hospitalized patients with COVID-19 (7).

Based on these data, we aimed to examine the pathogenesis of thromboembolic events in patients with COVID-19, current prophylaxis recommendations of international organizations, treatment dosage and duration, and the designs of ongoing studies.

\section{Pathogenesis}

Severe acute respiratory syndrome coronavirus 2 (SARS-CoV-2) can activate innate and adaptive immunity, but uncontrolled immune response can cause tissue damage. Patients with severe COVID-19 have increased pro-inflammatory cytokines and chemokines, such as interleukin-1 $\beta$ (IL-1 $\beta$ ) and IL-6, as well as IL-2R, IL-8, IL-17, granulocyte colony stimulating factor (G-CSF), granulocyte macrophage colony stimulating factor (GM-CSF) and tumor necrosis factor $\alpha$ (TNF- $\alpha$ ) and this is called "the cytokine storm". The increase in these pro-inflammatory cytokines may cause the process leading to multi-organ failure due to shock and tissue damage in patients with severe COVID-19 $(8,9)$. One of the most discussed issues in COVID-19 is coagulopathy, in which D-dimer and fibrinogen increase, and prothrombin time (PT) and activated partial thromboplastin time (aPTT) are prolonged. Tang et al. have shown that $15(71 \%)$ of 21 patients with COVID-19 who died had overt DIC in the late stage of the disease according to the International Society of Thrombosis and Haemostasis (ISTH) DIC criteria $(10,11)$. In a recently published meta-analysis, the pooled incidence of venous thromboembolism (VTE) in and out of intensive care unit (ICU) was $28 \%$, and $10 \%$, respectively (12). The rate of DVT detected using compression ultrasound was $32 \%$, and the pooled incidence of arterial thromboembolism was $3 \%$ (12). ISTH has reported that patients with severe COVID-19 usually present with single organ failure at the beginning of the disease, such as respiratory failure, and some patients may develop multiple organ damage in advanced stages. The main reason for multiple organ damage is the development of coagulopathy (13).

von Willebrand Factor (VWF) antigen and soluble P-selectin, which are endothelial cell and platelet activation markers, were significantly higher in patients with COVID-19 in ICU. VWF antigen and soluble thrombomodulin were associated with mortality in all inpatients with COVID-19 and COVID19-related coagulopathy was associated with endotheliopathy, the course of the disease and mortality (14). Thrombosis is prevented by the endothelial cell monolayer and the surface thrombomodulin in healthy alveolocapillary membrane. Pro-inflammatory cytokines, hypoxia, complement activation and neutrophil extracellular trap activation are triggers of endothelial cell damage in COVID-19. This activation causes Weibel-Palade body exocytosis and VWF and P-selectin release from endothelial cells (15). VWF can bind to platelets, neutrophils, and monocytes, forming a microthrombus and adhering to the vessel wall. In addition, thrombomodulin separates from the endothelial cell surface, becomes soluble and shows procoagulant properties. All this reveals that endotheliopathy plays a key role in COVID-19 vasculopathy (15).

Pro-angiogenic factors such as vascular endothelial growth factor (VEGF)-A, platelet derived growth factor (PDGF)-AA and PDGF-AB/BB were reported to be 
higher in patients with COVID-19 in non-ICU compared to the control group and this may help explain vascular remodeling (16). Angiopoietin-2, follistatin and plasminogen activator inhibitor-1 (PAI-1), which show endotheliopathy, were associated with hospital mortality in patients with COVID-19 in ICU. Endothelial cell function was affected by different mechanisms in critical and non-critical patients with COVID-19 (16).

Hypercoagulability, stasis, and vessel wall damage in Virchow Triad can be adapted to the development of thrombosis in COVID-19. Angiotensin converting enzyme (ACE) 2 receptor for SARS-CoV-2 was detected on the endothelial cell and disruption of fibrinolytic activity due to endothelial damage and VWF overexpression are factors that can initiate thrombosis. There is hyperviscosity in COVID-19. In the conventional capillary viscometer performed on 15 patients with COVID-19 in ICU, plasma viscosity was between 1.9-4.2 centipoise (CP; normal range 1.4-1.8) and thrombotic complications were detected in four patients with viscosities above $3.5 \mathrm{CP}$. Plasminogen inhibition, platelet dysfunction, complement activation, and hyperimmune syndrome may explain hypercoagulability (17-19).

\section{Current Literature}

As stated in our recently published article, which retrospectively included 154 patients with severe COVID-19, mortality was 6.5 times higher in patients using enoxaparin in prophylactic $(0.5 \mathrm{mg} / \mathrm{kg}$ twice a day [BID]) doses compared to those using enoxaparin in therapeutic $(1 \mathrm{mg} / \mathrm{kg}$ BID) doses. We reported that aggressive thromboprophylaxis should be considered in patients with severe COVID-19 (20). Similarly, a $50-60 \%$ reduction in mortality and VTE in patients with COVID-19 who received high-dose thromboprophylaxis compared to the standard dose was stated (21). Tang et al. have reported no significant differences in terms of 28-day mortality between patients treated with heparin and the control group in the study including 449 patients with COVID-19 (22). When the D-dimer level exceeded the normal upper limit by 6 -fold, mortality in the heparin group was significantly lower; however, heparin dose was not specified in this study (22). The incidence of thrombotic complications was $31 \%$, which mostly consisted of pulmonary embolism $(n=25,81 \%)$ in 184 patients with COVID-19 in ICU receiving at least standard thromboprophylaxis in the study by Klok et al (23). Although higher doses of thromboprophylaxis are usually recommended in patients with COVID-19 in the ICU, this study shows that thrombotic complications are high despite thromboprophylaxis (23). In the study conducted by Llitjos et al., $31 \%(n=8)$ of the 26 patients with COVID-19 in ICU were treated with prophylactic dose $\mathrm{LMWH}$ and $69 \%(\mathrm{n}=18)$ of them were treated with therapeutic dose LMWH (24). The incidence of VTE was significantly higher in the prophylactic treatment group compared to the therapeutic treatment group $(100 \%$ vs. $56 \%$, respectively, $p=0.03$ ). Consequently, early initiation of therapeutic anticoagulation was suggested in patients with severe COVID-19 in ICU (24). Atallah et al. have designed a patient-specific anticoagulation regimen for patients with COVID-19, in which therapeutic dose of anticoagulant (1 mg/kg BID) was recommended for patients with COVID-19 and a high risk of thromboembolism with no ICU admission or a low risk of thromboembolism with D-dimer levels $>3000 \mathrm{mcg} / \mathrm{L}$. If thromboembolism is detected on ultrasound, the therapeutic dose should be continued; if not, $40 \mathrm{mg}$ BID of enoxaparin is recommended (25). Khan et al. have recommended the use of $1.5 \mathrm{mg} / \mathrm{kg}$ enoxaparin once a day (OD) in patients with COVID-19 and D-dimer levels $>1000 \mathrm{ng} / \mathrm{ml}$ in the ICU. When creatinine clearance $(\mathrm{CrCl})$ is $<30 \mathrm{ml} / \mathrm{min}$ or D-dimer level $<1000 \mathrm{ng} / \mathrm{ml}$, $1 \mathrm{mg} / \mathrm{kg}$ enoxaparin OD was recommended (26).

There are differences about dosage in thromboprophylaxis because of the risk of bleeding. Eleven percent of the patients with COVID-19 and elevated risk of VTE were reported to have high bleeding risk according to Padua Prediction Scoring (27). In a cohort study in Denmark, major bleeding was observed in $47(0.5 \%)$ of 9460 patients with positive SARS-CoV-2 PCR (polymerase chain reaction) test and in $15(11 \%)$ of 132 patients who received thromboprophylaxis in ICU (28). Uncertainty over the dose for thromboprophylaxis seems like it will prevail until prospective studies on the risk of bleeding and VTE profit-loss are concluded.

Another issue that has not been clarified is whether extended thromboprophylaxis will be given after discharge or not. In the study of Salisbury et al. on 152 patients with COVID-19 without indications for anticoagulant use, $97 \%$ of them did not receive thromboprophylaxis at discharge, while only $3 \%$ were given a 7 -day prophylaxis. Symptomatic VTE rate was $2.6 \%$ in 42 days after discharge (29). In a prospective 
multi-center study including 1529 patients with COVID-19 discharged, 228 patients had symptoms of pulmonary embolism and DVT, 25 patients had been evaluated with imaging tests and only one patient was reported to have pulmonary embolism. After discharge, 51 (3.3\%) patients died, only two deaths were attributed to VTE. This result shows that routine extended thromboprophylaxis may not have clinical benefit (30).

\section{Current Thromboprophylaxis Recommendations for COVID-19 Patients}

WHO recommends pharmacological prophylaxis with LMWH such as enoxaparin for hospitalized patients with COVID-19 and have no contraindications. Mechanical thromboprophylaxis methods (such as intermittent pneumatic compression) are recommended for patients who have contraindications for medical therapy. However, there is no comment on the dose and the duration of prophylaxis, whether it should be continued at discharge, and the need for prophylaxis in outpatients (7).

The CHEST guideline suggests LMWH or fondaparinux over unfractionated heparin (UFH) in acutely ill hospitalized patients with COVID-19, and LMWH, fondaparinux or UFH over direct oral anticoagulant (DOAC). In critically ill patients with COVID-19, $\mathrm{LMWH}$ is recommended instead of $\mathrm{UFH}$, and $\mathrm{LMWH}$ or UFH is recommended instead of fondaparinux or DOAC. Standard dose over intermediate (LMWH BID or increased weight-based dosing) dose or full treatment dosing is recommended in acutely and critically ill patients with COVID-19. There is insufficient information about the risk of bleeding and elevated risk of VTE under standard dose thromboprophylaxis. Extended thromboprophylaxis was not recommended after discharge, but it was reported that it could be administered if new data on VTE risk and bleeding emerged after discharge (31).

American College of Cardiology reported that prophylactic anticoagulant treatment can be considered in outpatients with mild COVID-19 only if they are at elevated risk for VTE and low risk for bleeding. A prophylactic dose of anticoagulant (forty milligrams enoxaparin OD, or when $\mathrm{CrCl}<30 \mathrm{ml} / \mathrm{min}$, subcutaneous (SC) heparin $5000 \mathrm{U}$ BID or three times a day (TID) can be administered to an inpatient with moderate or severe COVID-19 without DIC. In a patient with moderate or severe COVID-19 and suspected or diagnosed DIC, a prophylactic dose is recommended in the absence of overt bleeding. A small group of researchers recommended intermediate $(29.7 \%)$ and therapeutic (16.2\%) doses. Routine screening for VTE risk at discharge is recommended to evaluate the need for thromboprophylaxis duration extension up to 45 days and direct prescription of prophylactics is not suggested (32).

ISTH recommends administering prophylactic dose of $\mathrm{LMWH}$ unless there is a contraindication (active bleeding or platelet $<25 \times 10^{9} / \mathrm{L}$ ) in all patients with COVID-19 requiring hospitalization (including non-critically ill patients) (13).

Scientific and Standardization Committee Clinical Guidance recommends prophylactic dose LMWH (preferred) or UFH for VTE prophylaxis in inpatients with COVID-19 not treated in ICU. Thirty percent of researchers suggest that intermediate-dose $\mathrm{LMWH}$ may also be considered. The dose can be modified for body weight, in case of severe thrombocytopenia (i.e., platelet counts of $50000 \times 10^{9}$ or $25000 \times 10^{9}$ per liter) and renal dysfunction. Prophylactic doses of LMWH or UFH may be considered for VTE prophylaxis in patients with COVID-19 in ICU, and fifty percent of investigators recommend considering intermediate-dose LMWH in high-risk patients with COVID-19. The dose can be increased by $50 \%$ based on body weight. Until randomized controlled trials are concluded, thrombophylaxis with therapeutic doses is not recommended. Multimodal thromboprophylaxis including medical therapy and mechanical methods is recommended by $60 \%$ of the researchers (33).

American Society of Hematology recommends pharmacological thrombophylaxis with LMWH over UFH (to reduce contact) in all inpatients with COVID-19 and have the risk of bleeding does not outweigh the risk of thrombosis. Fondaparinux is recommended in case of heparin-induced thrombocytopenia (HIT). Dose adjustment is recommended in patients with obesity. Mechanical thrombophylaxis can be used if there are contraindications for medical therapy, but their combination is not recommended. The use of thromboprophylaxis at therapeutic doses is not suggested in patients with COVID-19 in ICU. The evaluation of mobilization and bleeding risk should be done individually to decide to extent thromboprophylaxis duration after discharge from the hospital, however, no recommendation for treatment dose and duration has been offered (34). 
Anticoagulation Forum recommendations include standard dose thromboprophylaxis in non-critically ill patients with COVID-19. Increased doses (e.g., enoxaparin $40 \mathrm{mg}$ SC BID, enoxaparin $0.5 \mathrm{mg} / \mathrm{kg}$ SC BID, heparin 7500 units SC TID, or low-intensity heparin infusion) are suggested in patients with COVID-19 in ICU. Extended thromboprophylaxis should be evaluated individually and considered for patients who have a history of treatment in ICU, intubation, sedation, and paralysis, low risk of bleeding (e.g., IMPROVE bleeding score $<7.0$ ), and ongoing risk of VTE at discharge. Enoxaparin $40 \mathrm{mg}$ OD for 6-14 days, rivaroxaban $10 \mathrm{mg}$ OD for 31-39 days and betrixaban 160 mg once, and then $80 \mathrm{mg}$ OD for 35-42 days are recommended for extended thromboprophylaxis (35).

A standard dose of LMWH is recommended for VTE prophylaxis in acutely ill patients with COVID-19 unless there is a contraindication according to the National Institute for Health and Care Excellence (NICE) guideline. Fondaparinux or UFH is recommended if LMWH cannot be used. VTE prophylaxis should be continued during hospitalization or for seven days (whichever is longer). It is recommended to increase the prophylaxis dose to the intermediate dose (double the standard prophylactic dose), and daily evaluation for VTE and bleeding risk in patients who require advanced respiratory support (36).

Swiss Hematology Association recommends the use of standard dose $\mathrm{LMWH}$ according to risk scoring in all inpatients with COVID-19 if $\mathrm{CrCl}$ is $>30 \mathrm{ml} / \mathrm{min}$ and thromboprophylaxis is not contraindicated. If the patient weighs more than $100 \mathrm{~kg}, \mathrm{LMWH}$ dose should be increased. If $\mathrm{CrCl}$ is $<30 \mathrm{ml} / \mathrm{min}$, UFH SC $\mathrm{BID}$ or TID is recommended. An intermediate or therapeutic dose of LMWH or UFH is suggested according to the risk of bleeding in patients with COVID-19 in ICU and in patients who have excessive increase in D-dimer, severe inflammation, hepatic failure or renal failure or newly developing respiratory failure (37).

The Italian Society on Thrombosis and Haemostatis (SISET) recommends prophylaxis with $\mathrm{LMWH}, \mathrm{UFH}$ or fondaparinux in all inpatients with COVID-19. Intermediate dose of LMWH (e.g., enoxaparin 4000 IU SC BID) may be considered in patients with COVID-19 and have multiple risk factors including body mass index $>30 \mathrm{~kg} / \mathrm{m}^{2}$, previous VTE, active cancer for VTE. Although this seems as a reasonable approach, the use of therapeutic doses of UFH or
LMWH is currently not supported by current evidence except established diagnoses of VTE. It is recommended to continue VTE prophylaxis for 7-14 days after discharge for patients with COVID-19 (38) (Table 1).

Considering the ongoing prospective randomized controlled studies, the most frequently studied issue is the LMWH dose to be used in thromboprophylaxis in inpatients with COVID-19 treated and not treated in ICU (39-49). There are also studies on the use of DOAC drugs, such as rivaroxaban (43,50-52), apixaban $(53,54)$ and edoxaban $(49)$ for thromboprophylaxis. The results of studies on rivaroxaban $(51,52)$, apixaban (54) and edoxaban (49) for extended thromboprophylaxis in patients with COVID-19 after discharge or outpatients with COVID-19 will provide valuable results to guide clinicians.

In conclusion, thromboembolism is frequently diagnosed in patients with COVID-19, and thromboprophylaxis is recommended in inpatients with COVID19. Although other agents such as DOAC that may be used for thromboprophylaxis, the most recommended agent for pharmacological prophylaxis is $\mathrm{LMWH}$ (especially enoxaparin). The balance between VTE and bleeding risk is very important and decisive in this regard. Thromboprophylaxis proposals based on D-dimer, VTE risk and IMPROVE (55) bleeding risk score in COVID-19 patients are summarized in Figure 1. Though IMPROVE has been recommended for COVID-19 patients, it was published before COVID19. There is still a debate on D-dimer and prophylaxis decisions because $\mathrm{D}$-dimer is a diagnostic test for venous thrombosis. In the current COVID-19 treatment guideline of the Turkish Ministry of Health, the risk of thromboembolic events is high in patients with elevated D-dimer levels ( $>2$ times the upper limit of normal $[\mathrm{ULN}]$ ) and it is recommended that thromboprophylaxis should be extended to 45 days (56). Furthermore, Scientific and Standardization Committee of the International Society on Thrombosis and Haemostasis defined that thromboembolic events may develop and lead to poor prognosis when D-dimer levels increase more than six times ULN (33). According to these current guidelines, D-dimer levels were used in the decision of thromboprophylaxis in this review. The dosage and the duration of anticoagulation in inpatients with COVID-19 and the requirement for extended thromboprophylaxis after discharge will be clarified with the results of randomized controlled studies. 
Table 1. Current thromboprophylaxis recommendations for patients with COVID-19

Guidelines

WHO (7)

VTE prophylaxis in acutely ill hospitalized pts with COVID-19.

VTE prophylaxis in critically ill

CHEST(31) hospitalized pts with COVID-19.

VTE prophylaxis after hospital discharge

VTE prophylaxis in outpatients with COVID-19.

VTE prophylaxis in hospitalized pts with moderate/severe COVID-19 without DIC

ACC (32)

VTE prophylaxis in hospitalized pts with moderate/severe COVID-19 and suspected or confirmed DIC

VTE extended thromboprophylaxis after discharge

VTE prophylaxis in pts with COVID-19 requiring hospitalization (including noncritically ill pts.)

VTE prophylaxis in hospitalized (not in ICU) pts with COVID-19.

ISTH SSC (33)

VTE prophylaxis in pts with COVID-19 in ICU.

VTE prophylaxis in all hospitalized pts with COVID-19.

ASH (34)

VTE extended thromboprophylaxis after discharge

VTE prophylaxis in non-critically ill pts with COVID-19.

Anticoagulation Forum (35)

VTE prophylaxis in pts with COVID-19 in ICU.

VTE extended thromboprophylaxis after discharge

VTE prophylaxis in acutely ill pts with COVID-19.

NICE (36)
VTE prophylaxis in pts with COVID-19 and requiring advanced respiratory support

\section{Recommendation}

Recommended LMWH (e.g. enoxaparin), according to local and international standards

Recommended LMWH or fondaparinux at standard doses over intermediate or treatment dose or over DOAC

Recommended LMWH or UFH at standard doses over intermediate or treatment dose or over fondaparinux or DOAC

Recommended inpatient thromboprophylaxis only over inpatient plus extended thromboprophylaxis after hospital discharge.

Not recommended. Could be considered after risk assessment (elevated VTE without high bleeding risk)

Consider prophylactic doses of anticoagulation (e.g. enoxaparin $40 \mathrm{mg} \mathrm{OD}$; if $\mathrm{CrCl}<30 \mathrm{~mL} / \mathrm{min}$, use UFH $5000 U$ BID or TID

Consider prophylactic doses without overt bleeding. $29.7 \%$ of investigators voted for intermediate-dose and $16.2 \%$ voted for therapeutic dose.

Recommended VTE risk screening for prophylaxis decision up to 45 days

Recommended LMWH at prophylactic dose without contraindications (active bleeding or platelet $<25 \times 10^{9} / \mathrm{L}$ )

Recommended LMWH (preferred) or UFH at prophylactic doses $(30 \%$ of investigators voted for intermediate-dose LMWH)

Recommended LMWH or UFH at prophylactic doses $(50 \%$ of investigators voted for intermediatedose LMWH for elevated risk of VTE)

Recommended LMWH over UFH (to reduce contact) when the risk of bleeding does not outweigh the risk of VTE

Recommended to assess mobilization and bleeding risk individually, there was no dose and duration recommendation.

Recommended LMWH standard doses

Recommended increased doses (enoxaparin $40 \mathrm{mg}$ SC BID, enoxaparin $0.5 \mathrm{mg} / \mathrm{kg}$ SC BID, heparin 7500 units SC TID, or low-intensity heparin infusion)

Not recommended routinely; should be evaluated individually

Recommended LMWH standard doses over UFH or fondaparinux

Recommended to increase the prophylactic dose to intermediate dose (double the standard dose) while daily assessing VTE and bleeding risk 
Table 1. Current thromboprophylaxis recommendations for patients with COVID-19 (continue)

\section{Guidelines}

\section{Patients}

VTE prophylaxis in all hospitalized pts with COVID-19.

VTE prophylaxis in pts with COVID-19 in ICU.

\section{Recommendation}

Recommended LMWH or UFH, unless contraindicated

Recommended LMWH or UFH at intermediate or therapeutic doses, according to bleeding risk, in pts. with an elevation D-dimer, severe inflammation, sign of hepatic or renal dysfunction or acute respiratory failure

VTE prophylaxis in all hospitalized COVID-19 pts.

SISET (38)
Recommended LMWH, UFH or fondaparinux at standard dose, Intermediate-dose LMWH (e.g. enoxaparin 4000IU BID) in pts with multiple risk factors for VTE (BMI $30 \mathrm{~kg} / \mathrm{m}^{2}$, previous VTE, active cancer, etc.)

VTE extended thromboprophylaxis after Recommended for 7-14 days in case of pre-existing discharge or persisting VTE risk factors

WHO: World Health Organization, VTE: Venous thromboembolism, pts: Patients, LMWH: Low molecular weight heparin, UFH: Unfractionated heparin, DOAC: Direct oral anticoagulant, ACC: American College of Cardiology, COVID-19: Coronavirus disease 19, DIC: Disseminated intravascular coagulation, OD: Once daily, BID: Twice a day, TID: Three times a day, CrCl: Creatinine clearance, ISTH: International Society of Thrombosis and Haemostatis, SSC: Scientific and Standardization Committee, ICU: Intensive care unit, ASH: American Society of Hematology, SC: Subcutaneous, NICE: National Institute for Health and Care Excellence, SH: Society of Haematology, SISET: Italian Society on Thrombosis and Haemostatis, BMI: Body mass index, ECMO: Extracorporeal membrane oxygenation.

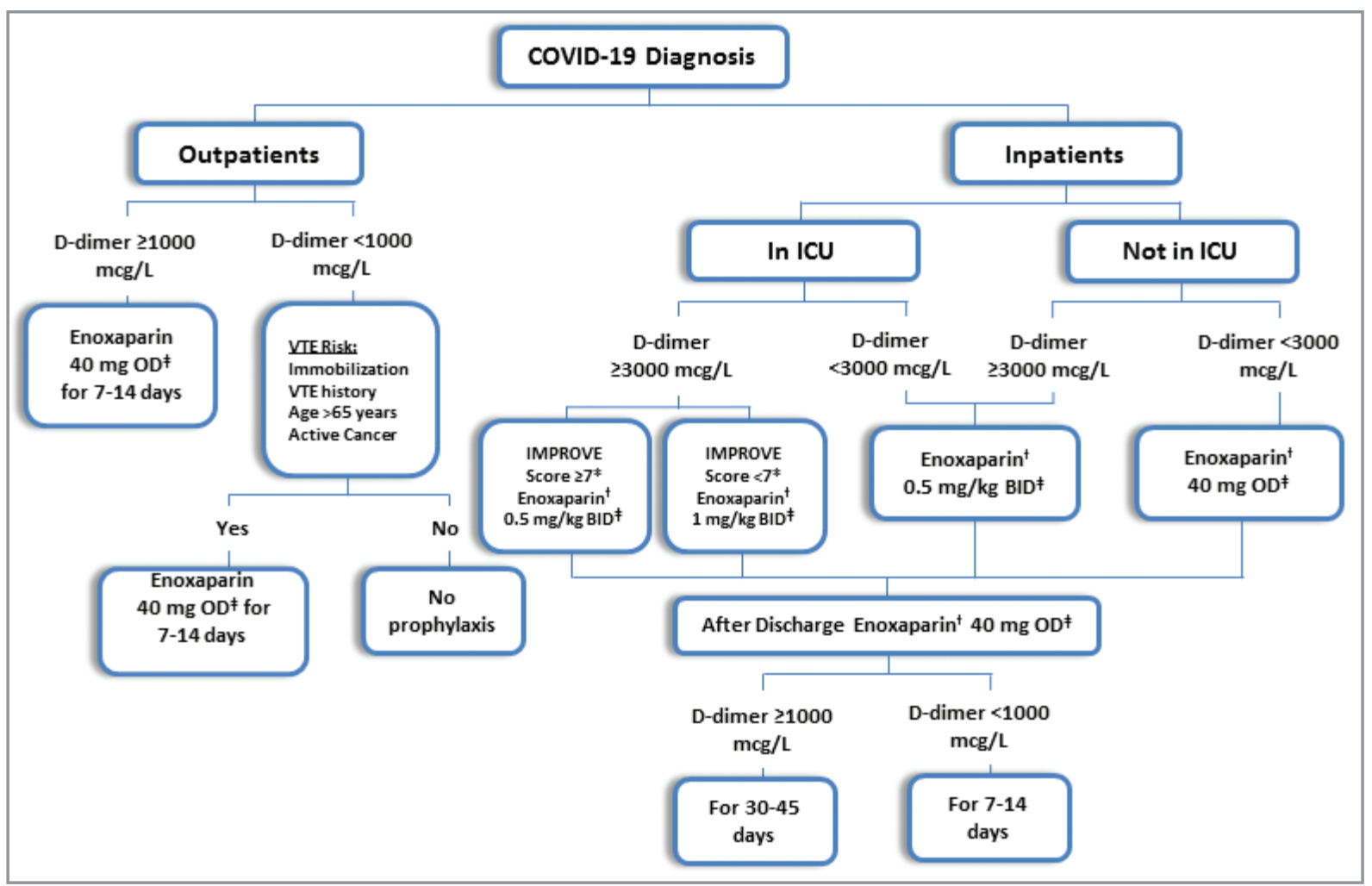

Figure 1. Proposed algorithm for thromboprophylaxis of patients with COVID-19.

* Improve score: International medical prevention registry of venous thromboembolism bleeding risk score (55).

+ If HIT occurs, fondaparinux should be used.

‡ The dose should be adjusted according to $\mathrm{CrCl}$ and BMI.

OD: Once daily, VTE: Venous thromboembolism, ICU: Intensive care unit, BID: Twice a day, HIT: Heparin-induced thrombocytopenia, $\mathrm{CrCl}$ : Creatinine clearance, BMI: Body mass index. 


\section{REFERENCES}

1. World Health Organization (WHO). WHO DirectorGeneral's opening remarks at the media briefing on COVID-19. Available from: https://www.who.int/director-general/speeches/detail/who-director-general-s-opening-remarks-at-the-media-briefing-on-covid-19---11march-2020 (Accessed date: 5 Jan 2021).

2. Barek MA, Aziz MA, Islam MS. Impact of age, sex, comorbidities and clinical symptoms on the severity of COVID19 cases: A meta-analysis with 55 studies and 10014 cases. Heliyon 2020; 6(12): e05684.

3. World Health Organization (WHO). WHO Coronavirus Disease (COVID-19) Dashboard. Available from: https:// covid19.who.int/ (Accessed date: 5 Jan 2021).

4. Marongiu F, Grandone E, Barcellona D. Pulmonary thrombosis in 2019-nCoV pneumonia? I Thromb Haemost 2020; 18(6): 1511-13.

5. Ackermann M, Verleden SE, Kuehnel M, Haverich A, Welte $T$, Laenger $F$, et al. Pulmonary Vascular Endothelialitis, Thrombosis, and Angiogenesis in Covid-19. N Engl J Med 2020; 383(2): 120-8.

6. Wichmann D, Sperhake IP, Lütgehetmann M, Steurer $S$, Edler C, Heinemann A, et al. Autopsy findings and venous thromboembolism in patients with COVID-19: A Prospective Cohort Study. Ann Intern Med 2020; 173(4): 268-77.

7. World Health Organization (WHO). Clinical management of COVID-19 interim guidance. Available from: https:// www.who.int/publications/i/item/clinical-management-of-covid-19 (Accessed date: 6 Jan 2021).

8. Cao X. COVID-19: immunopathology and its implications for therapy. Nat Rev Immunol 2020; 20(5): 269-70.

9. Qin C, Zhou L, Hu Z, Zhang S, Yang S, Tao Y, et al. Dysregulation of Immune Response in Patients With Coronavirus 2019 (COVID-19) in Wuhan, China. Clin Infect Dis 2020; 71(15): 762-8.

10. Panigada $M$, Bottino $N$, Tagliabue P, Grasselli G, Novembrino C, Chantarangkul V, et al. Hypercoagulability of COVID-19 patients in intensive care unit: A report of thromboelastography findings and other parameters of hemostasis. J Thromb Haemost 2020; 18(7): 1738-42.

11. Tang N, Li D, Wang X, Sun Z. Abnormal coagulation parameters are associated with poor prognosis in patients with novel coronavirus pneumonia. I Thromb Haemost 2020; 18(4): 844-7.

12. Boonyawat $K$, Chantrathammachart $P$, Numthavaj $P$, Nanthatanti N, Phusanti S, Phuphuakrat A, et al. Incidence of thromboembolism in patients with COVID-19: a systematic review and meta-analysis. Thromb I 2020; 18(1): 34.

13. Thachil J, Tang N, Gando S, Falanga A, Cattaneo M, Levi $M$, et al. ISTH interim guidance on recognition and management of coagulopathy in COVID-19. I Thromb Haemost 2020; 18(5): 1023-6.
14. Goshua G, Pine AB, Meizlish ML, Chang CH, Zhang $H$, Bahel P, et al. Endotheliopathy in COVID-19-associated coagulopathy: evidence from a single-center, cross-sectional study. Lancet Haematol 2020; 7(8): e575-82.

15. O'Sullivan IM, Gonagle DM, Ward SE, Preston RJS, O'Donnell JS. Endothelial cells orchestrate COVID-19 coagulopathy. Lancet Haematol 2020; 7(8): e553-5.

16. Pine AB, Meizlish ML, Goshua G, Chang CH, Zhang $H$, Bishai J, et al. Circulating markers of angiogenesis and endotheliopathy in COVID-19. Pulm Circ 2020; 10(4): 2045894020966547.

17. Ahmed S, Zimba O, Gasparyan AY. Thrombosis in Coronavirus disease 2019 (COVID-19) through the prism of Virchow's triad. Clin Rheumatol 2020; 39(9): 2529-43.

18. Varga Z, Flammer Al, Steiger $P$, Haberecker $M$, Andermatt $R$, Zinkernagel $A S$, et al. Endothelial cell infection and endotheliitis in COVID-19. Lancet 2020; 395(10234): 1417-18.

19. Maier CL, Truong AD, Auld SC, Polly DM, Tanksley CL, Duncan A. COVID-19-associated hyperviscosity: a link between inflammation and thrombophilia? Lancet 2020; 395(10239): 1758-9.

20. Canoglu K, Saylan B. Therapeutic dosing of low-molecular-weight heparin may decrease mortality in patients with severe COVID-19 infection. Ann Saudi Med 2020; 40(6): 462-8.

21. Martinelli I, Ciavarella A, Abbattista $M$, Aliberti S, De Zan $V$, Folli $C$, et al. Increasing dosages of low-molecular-weight heparin in hospitalized patients with Covid-19. Intern Emerg Med 2021; 1-7.

22. Tang N, Bai H, Chen X, Gong J, Li D, Sun Z. Anticoagulant treatment is associated with decreased mortality in severe coronavirus disease 2019 patients with coagulopathy. I Thromb Haemost 2020; 18(5): 1094-9.

23. Klok FA, Kruip MJHA, van der Meer NJM, Arbous MS, Gommers DAMPJ, Kant KM, et al. Incidence of thrombotic complications in critically ill ICU patients with COVID19. Thromb Res 2020; 191: 145-7.

24. Llitjos JF, Leclerc M, Chochois C, Monsallier JM, Ramakers $M$, Auvray M, et al. High incidence of venous thromboembolic events in anticoagulated severe COVID-19 patients. J Thromb Haemost 2020; 18(7): 1743-6.

25. Atallah B, Mallah SI, AlMahmeed W. Anticoagulation in COVID-19. Eur Heart I Cardiovasc Pharmacother 2020; 6(4): $260-1$.

26. Khan IH, Savarimuthu S, Leung MST, Harky A. The need to manage the risk of thromboembolism in COVID-19 patients. J Vasc Surg 2020; 72(3): 799-804.

27. Wang T, Chen R, Liu C, Liang W, Guan W, Tang R, et al. Attention should be paid to venous thromboembolism prophylaxis in the management of COVID-19. Lancet Haematol 2020; 7(5): e362-3. 
28. Dalager-Pedersen $M$, Lund $L C$, Mariager $T$, Winther $R$, Hellfritzsch $M$, Larsen TB, et al. Venous thromboembolism and major bleeding in patients with COVID-19: A nationwide population-based cohort study. Clin Infect Dis 2021; ciab003.

29. Salisbury R, lotchkova V, Jaafar S, Morton J, Sangha G, Shah $A$, et al. Incidence of symptomatic, image-confirmed venous thromboembolism following hospitalization for COVID-19 with 90-day follow-up. Blood Adv 2020; 4(24): 6230-9.

30. Rashidi F, Barco S, Kamangar F, Heresi GA, Emadi A, Kaymaz $C$, et al. Incidence of symptomatic venous thromboembolism following hospitalization for coronavirus disease 2019: Prospective results from a multi-center study. Thromb Res 2020; 198: 135-8.

31. Moores LK, Tritschler T, Brosnahan S, Carrier M, Collen JF, Doerschug K, et al. Prevention, Diagnosis, and Treatment of VTE in Patients With Coronavirus Disease 2019: CHEST Guideline and Expert Panel Report. Chest 2020; 158(3): 1143-63.

32. Bikdeli B, Madhavan MV, Jimenez D, Chuich T, Dreyfus I, Driggin E, et al; Global COVID-19 Thrombosis Collaborative Group, Endorsed by the ISTH, NATF, ESVM, and the IUA, Supported by the ESC Working Group on Pulmonary Circulation and Right Ventricular Function. COVID-19 and Thrombotic or Thromboembolic Disease: Implications for Prevention, Antithrombotic Therapy, and Follow-Up: JACC State-of-the-Art Review. I Am Coll Cardiol 2020; 75(23): 2950-73.

33. Spyropoulos AC, Levy JH, Ageno W, Connors JM, Hunt BJ, Iba $T$, et al; Subcommittee on Perioperative, Critical Care Thrombosis, Haemostasis of the Scientific, Standardization Committee of the International Society on Thrombosis and Haemostasis. Scientific and Standardization Committee communication: Clinical guidance on the diagnosis, prevention, and treatment of venous thromboembolism in hospitalized patients with COVID-19. I Thromb Haemost 2020; 18(8): 1859-65.

34. American Society of Hematology COVID-19 Resources. COVID-19 and VTE/Anticoagulation: Frequently Asked Questions. Available from: https://www.hematology.org/ covid-19/covid-19-and-vte-anticoagulation (Accessed date: 10 Jan 2021).

35. Barnes GD, Burnett A, Allen A, Blumenstein M, Clark NP, Cuker $A$, et al. Thromboembolism and anticoagulant therapy during the COVID-19 pandemic: interim clinical guidance from the anticoagulation forum. I Thromb Thrombolysis 2020; 50(1): 72-81.

36. National Institute for Health and Care Excellence. COVID19 rapid guideline: reducing the risk of venous thromboembolism in over 16s with COVID-19. NICE guideline. Available from: https://www.nice.org.uk/guidance/ ng186/resources/covid19-rapid-guideline-reducing-therisk-of-venous-thromboembolism-in-over-16s-withcovid19-pdf-66142025041093 (Accessed date: 10 Jan 2021).
37. Casini A, Alberio L, Angelillo-Scherrer A, Fontana P, Gerber $B$, Graf $L$, et al. Thromboprophylaxis and laboratory monitoring for in-hospital patients with COVID-19 - a Swiss consensus statement by the Working Party Hemostasis. Swiss Med Wkly 2020; 150: w20247.

38. Marietta M, Ageno W, Artoni A, De Candia E, Gresele P, Marchetti M, et al. COVID-19 and haemostasis: a position paper from Italian Society on Thrombosis and Haemostasis (SISET). Blood Transfus 2020; 18(3): 167-9.

39. Anti-thrombotics for Adults Hospitalized With COVID-19 (ACTIV-4). ClinicalTrials.gov Identifier: NCT04505774. Available from: https://www.clinicaltrials.gov/ct2/show/ NCT04505774 (Accessed date: 13 Jan 2021).

40. A Pragmatic Randomized Controlled Trial of Therapeutic Anticoagulation Versus Standard Care as a Rapid Response to (SARS-CoV-2) COVID-19 Pandemic (RAPID-BRAZIL). ClinicalTrials.gov Identifier: NCT04444700. Available from: https://www.clinicaltrials.gov/ct2/show/ NCT04444700 (Accessed date: 13 Jan 2021).

41. Full Dose Heparin Vs. Prophylactic Or Intermediate Dose Heparin in High Risk COVID-19 Patients (HEP-COVID Trial). ClinicalTrials.gov Identifier: NCT044401293. Available from: https://www.clinicaltrials.gov/ct2/show/ NCT044401293 (Accessed date: 13 Jan 2021).

42. Preventing COVID-19 Complications With Low- and Highdose Anticoagulation (COVID-HEP). ClinicalTrials.gov Identifier: NCT04345848. Available from: https://www. clinicaltrials.gov/ct2/show/NCT04345848 (Accessed date: 13 Jan 2021).

43. Full Anticoagulation Versus Prophylaxis in COVID-19: COALIZAO ACTION Trial (ACTION). ClinicalTrials.gov Identifier: NCT04394377. Available from: https://www. clinicaltrials.gov/ct2/show/NCT04394377 (Accessed date: 13 Jan 2021).

44. Coagulopathy of COVID-19: A Pragmatic Randomized Controlled Trial of Therapeutic Anticoagulation Versus Standard Care as a Rapid Response to the COVID-19 Pandemic (RAPID COVID COAG). ClinicalTrials.gov Identifier: NCT04362085. Available from: https://www. clinicaltrials.gov/ct2/show/NCT04362085 (Accessed date: 13 Jan 2021).

45. Intermediate or Prophylactic-Dose Anticoagulation for Venous or Arterial Thromboembolism in Severe COVID19 (IMPROVE). ClinicalTrials.gov Identifier: NCT04367831. Available from: https://www.clinicaltrials. gov/ct2/show/NCT04367831 (Accessed date: 13 Jan 2021).

46. Prevention of Arteriovenous Thrombotic Events in Critically-III COVID-19 Patients Trial (COVID-PACT). ClinicalTrials.gov Identifier: NCT04409834. Available from: https://www.clinicaltrials.gov/ct2/show/ NCT04367831 (Accessed date: 14 Jan 2021). 
47. Intermediate-dose vs Standard Prophylactic Anticoagulation and Statin vs Placebo in ICU Patients With COVID-19 (INSPIRATION). ClinicalTrials.gov Identifier: NCT04486508. Available from: https://www. clinicaltrials.gov/ct2/show/NCT04486508 (Accessed date: 14 Jan 2021).

48. High Versus Low LMWH Dosages in Hospitalized Patients With Severe COVID-19 Pneumonia and Coagulopathy (COVID-19 HD). ClinicalTrials.gov Identifier: NCT04408235. Available from: https://www.clinicaltrials. gov/ct2/show/NCT04408235 (Accessed date: 14 Jan 2021).

49. Hamburg Edoxaban for Anticoagulation in COVID-19 Study (HERO-19). ClinicalTrials.gov Identifier: NCT04542408. Available from: https://www.clinicaltrials. gov/ct2/show/NCT04542408 (Accessed date: 14 Jan 2021).

50. Effect of Anticoagulation Therapy on Clinical Outcomes in COVID-19 (COVID-PREVENT). ClinicalTrials.gov Identifier: NCT04416048. Available from: https://www. clinicaltrials.gov/ct2/show/NCT04416048 (Accessed date: 14 Jan 2021).

51. A Study of Rivaroxaban to Reduce the Risk of Major Venous and Arterial Thrombotic Events, Hospitalization and Death in Medically III Outpatients With Acute, Symptomatic Coronavirus Disease 2019 (COVID-19) Infection (PREVENT-HD). ClinicalTrials.gov Identifier: NCT04508023. Available from: https://www.clinicaltrials. gov/ct2/show/NCT04508023 (Accessed date: 15 Jan 2021).
52. Medically III Hospitalized Patients for COVID-19 THrombosis Extended ProphyLaxis With Rivaroxaban ThErapy: The MICHELLE Trial (MICHELLE). ClinicalTrials. gov Identifier: NCT04662684. Available from: https:// www.clinicaltrials.gov/ct2/show/NCT04662684 (Accessed date: 15 Jan 2021).

53. FREEDOM COVID-19 Anticoagulation Strategy (FREEDOM COVID). ClinicalTrials.gov Identifier: NCT04512079. Available from: https://www.clinicaltrials. gov/ct2/show/NCT04512079 (Accessed date: 15 Jan 2021).

54. COVID-19 Positive Outpatient Thrombosis Prevention in Adults Aged 40-80. ClinicalTrials.gov Identifier: NCT04498273. Available from: https://www.clinicaltrials. gov/ct2/show/NCT04498273 (Accessed date: 15 Jan 2021).

55. Decousus $H$, Tapson VF, Bergmann JF, Chong BH, Froehlich JB, Kakkar AK, et al; IMPROVE Investigators. Factors at admission associated with bleeding risk in medical patients: findings from the IMPROVE investigators. Chest 2011; 139(1): 69-79.

56. Republic of Turkey Ministry of Health. Guide of COVID19 (SARS-CoV-2 infection). Available from: https:// covid19.saglik.gov.tr/Eklenti/39296/0/covid-19rehberiantisitokin-antiinflamatuartedavilerkoagulopatiyonetimipdf. pdf (Accessed date: 30 Apr 2021). 